\title{
MILK PRODUCT PACKAGING FEATURES AS THE KEY FACTOR OF SUCCESSFUL CANVASSING TECHNIQUES
}

\author{
Jana Rybanska ${ }^{1}$, Mgr. Mgr., PhD.; Ludmila Nagyova², Prof., Ing., PhD. and \\ Elena Horska ${ }^{3}$, Prof., Dr., Ing. \\ 1,2,3 Department of Marketing and Trade, Faculty of Economics and Management, Slovak University \\ of Agriculture in Nitra
}

\begin{abstract}
The perception and final choice of selected milk products depends on various factors. Presented paper deals with the research of potential packages of selected milk products to find out possible associations that consumers have with these products. Associations of consumers with packaging features play an important role in the overall perception of these food products. Packages, also known as the "silent sellers" can attract consumers very quickly. The research sample consists of 320 young adults, aged 20 - 45. All respondents belong to the segment of "Generation $Y$ " or "Millennials". Participants aged 20 - 45 were chosen intentionally because they represent the target sample for milk products. They are likely to have conscious patterns for milk products consumption gained during childhood, they are mostly independent and take care of their own families or prepare for their future family or career. They have the power to influence the choices of next generations. From our study we can conclude that features and visual cues that create the strongest associations in the mind of a consumer can significantly influence the overall perception of the product. When a consumer can find an association (a sound, a picture, a memory etc.) inside his subconscious mind, we can assume that there is an emotional connection present. It was also found out that consumers prefer traditional packages connected with Slovak customs and traditions to more modern packages. Packages with traditional Slovak motives are strongly associated with nature, farming, home production and high quality.
\end{abstract}

Key words: milk product, milk, packaging, consumer choice, consumer behaviour. JEL code: M31, M37, M39.

\section{Introduction}

Milk and milk products have long been associated with good health, making them one of the most consumed products throughout the countries in the world. Milk has long been seen as a healthy beverage, because it is high in a range of nutrients (Ware and Wilson, 2017). It is a rich source of quality protein that contains all nine essential amiNo acids that may help reduce age-related muscle loss and promote muscle repair. Milk also contains a variety of nutrients that benefit bone health, such as calcium, vitamin D, phosphorus and magnesium (Kubala, 2018). In Slovak Republic, the consumption of milk is closely connected with the culture and history of the Slovak nation. For years, the milk of different kinds and products made of milk have been the precious source of energy and proteins and in many cases the only obtainable food. Cheeses have very often replaced meat, mainly during less happy periods of our history when the significant part of Slovak population struggled with the poverty, but also nowadays.

In our country, milk and milk products represent the considerable part of consumer's diet. The production of milk and milk products have been increasing since 2012 (Fig. 1). However, the consumption of milk and milk products is quite irregular and represents only a half of the recommended dose. The estimated average consumption of milk in 2017 in Slovakia was about 176 $\mathrm{kg}$ per capita. The estimated average consumption of cheeses in 2017 was about 13,7 kg per capita (Masar, 2018). The consumption of sheep and goat milk is much lower than the consumption of cow milk. It is mainly because the livestock production in Slovak Republic is mainly focused on beef cattle. The irregularity in consumption of milk can be caused by changes in life-style trends. Currently, mainly plant milks are promoted because many experts believe that the livestock production harms the environment, and thus the health of people. 
Source: authors' elaboration according to Masar (2018)

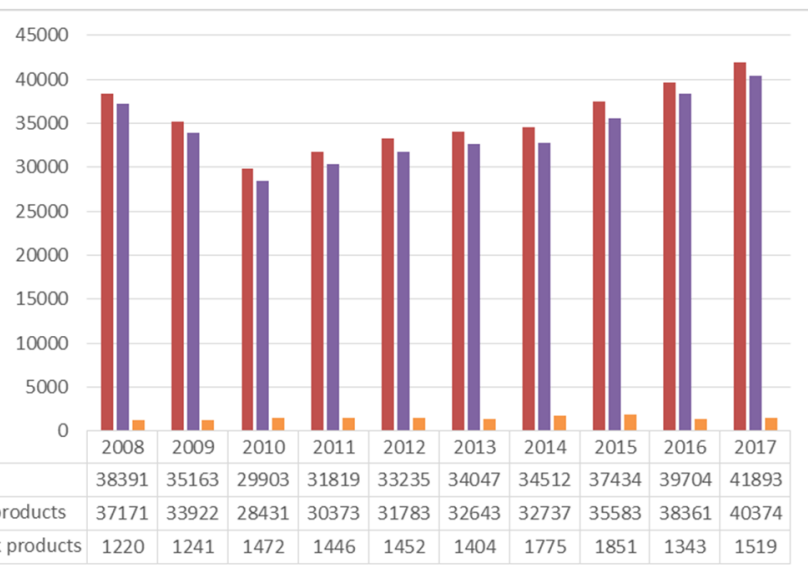

Fig. 1. Production of milk and milk products in Slovak Republic

Culture, traditions, agriculture and nature represent factors that are strongly connected with observed and investigated milk products. Previous research has demonstrated that the way in which information is presented affects the process of evaluation and the final consumer choice (Levin, 1987). Consumer choice is traditionally considered to be a rational, well-judged cognitive process. Increasingly however, research has shown that a significant part of consumer decision-making is unconscious (Fitzsimons et al., 2002). Clegg (2000), Dijksterhuis et al. (2005), Dhar (2012), Krishna et al. (2014) and others found that only limited number of consumer choices are based on conscious information-processing strategies. A significant part of consumer choices is unconscious and results from different cues present in the environment of individuals. Many experimental studies in consumer behaviour research and social psychology have confirmed that environmental cues together with various factors strongly influence the final consumer choice (Jacob et al., 2011). Food packaging plays an important role in attracting consumers' attention and generating expectations in the consumer that in turn affect their product perception and buying behaviour (Gelici-Zeko et al., 2012).

The presented paper investigates the persuading power of visual aspects and associations that consumers have with selected milk products, specifically sheep and cow cheeses. It explores modern and classical graphical designs including designs related to historical features of agriculture, milk production, countryside, livestock or any other symbols associated with traditional way of farming on the land. Our goal is to find out how these packages are perceived by selected category of consumers.

The research sample consists of 320 young adults (200 women and 120 men), aged 20 - 45. All respondents, according to their age structure, belong to the segment of "Generation $Y$ " or "Millennials". Participants aged 20 - 45 were chosen intentionally because they represent the target sample for milk products. They are likely to have conscious patterns for milk products consumption gained during childhood, they are mostly independent and take care of their own families or prepare for their future family or career. They have the power to influence the choices of next generations, that is why we consider them to be the most important segment on the market of milk products. All respondents have completed a minimum of secondary education and they live in Slovak Republic. Further characteristics of participants are stated in following Table (Table 1). 
Table 1

\section{Participants according to gender and residence}

Source: authors' elaboration

\begin{tabular}{|c|c|c|c|c|}
\hline \multicolumn{2}{|c|}{} & \multicolumn{2}{c|}{ Residence } & \multirow{2}{*}{ Total } \\
\cline { 3 - 4 } \multirow{2}{*}{ Gender } & Town & Village & \\
\hline & Male & 70 & 50 & 120 \\
\cline { 2 - 4 } & Female & 102 & 98 & 200 \\
\hline \multicolumn{2}{r|}{ Total } & $\mathbf{1 7 2}$ & $\mathbf{1 4 8}$ & $\mathbf{3 2 0}$ \\
\hline
\end{tabular}

The representativeness of the sample was verified by a Pearson's Chi-square test. It was found out that the sample of respondents is representative according to gender and residence.

The research consists of several phases. At first, the association experiment was conducted. Respondents were asked to write down at least 3 words that they have associated with the word "cheese". Then they were presented 3 different types of cheese (Fig. 4). They were not given any other information about cheeses, they could only see the pictures. They were again asked to write down at least 3 associations for every picture. Selected cheeses are well-known for Slovak consumers. The first one is typical sheep milk product called "Parenica", which can be smoked or fresh and is very popular among Slovak consumers. It can be bought in the most of stores and farms. The second one is also made from sheep milk, it is a very typical chalet product called "Korbaciky". It is basically a sheep cheese strings weaved into the shape of a whip and it is possible to buy it everywhere, but it is generally considered to be a farm-to-Table product in the country. The last one is a typical cheese made of cow milk (Emmental type).
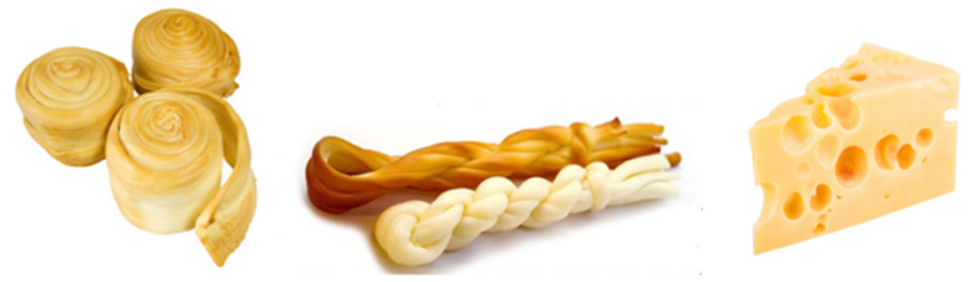

Source: authors' elaboration

Fig. 2. Cheeses used in the association experiment

On the basis of results of the association experiment 2 logos for every type of cheese were designed (Fig. 5, Fig. 6 and Fig. 7). One that contains one or more associated features (according to the results of experiment) and one that contains also other features. Designed logos were subsequently evaluated by the research sample (a week later). Respondents were divided into two groups. The first group of respondents (100 women and 60 men) was not given any information, they were told to choose the logo that they prefer. The second group of respondents (100 women and 60 men) were told that they are going to choose the logo for the farm-to-Table products. Consumers evaluated designed logos on the scales of semantic differential.
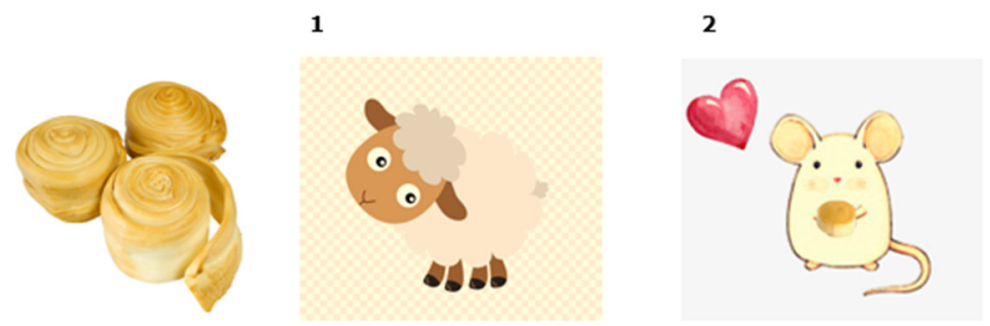

Source: authors' elaboration

Fig. 3. Designed logos for the „Parenica” sheep cheese 


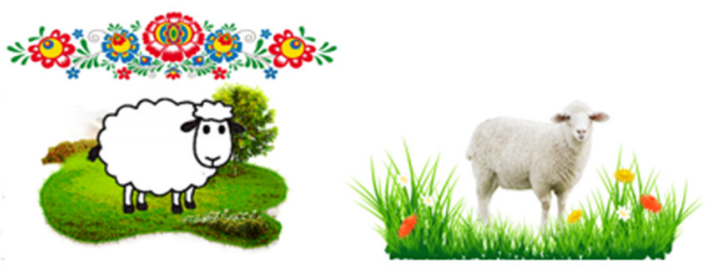

Fig. 4. Designed logos for the „Korbaciky sheep cheese

1

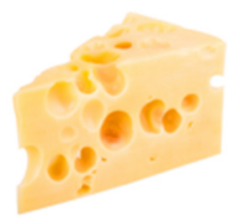

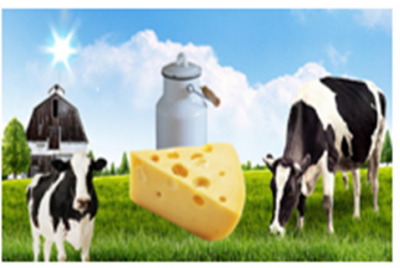

2

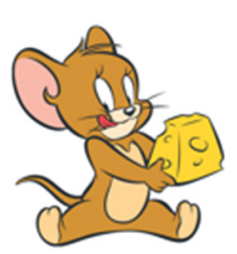

Source: own elaboration

Fig. 5. Designed logos for the cow cheese

\section{Research results and discussion}

Results of the association experiment are showed in the following Table (Table 2). For every item we chose the most important and the most often associated words that were stated by the respondents. We took into consideration only positive or neutral associated words.

\section{Results of the association experiment}

\begin{tabular}{|l|l|}
\hline \multicolumn{1}{|c|}{ Words (Pictures) } & \multicolumn{1}{c|}{ Associations } \\
\hline Cheese & $\begin{array}{l}\text { sheep, nature, health, Liptov, yummy, eidam, gouda, mozarella, string } \\
\text { cheese }\end{array}$ \\
\hline „Parenica” cheese (Fig. 3) & sheep, tradition, mountains, Liptov, smoked, yummy, nature \\
\hline „Korbaciky" cheese (Fig. 4) & $\begin{array}{l}\text { sheep, farm, chalet, Tatras, mountains, shepherd, salty, yummy, } \\
\text { nature, culture }\end{array}$ \\
\hline Cow cheese (Fig. 5) & $\begin{array}{l}\text { Tom\&Jerry, cow, milk, yummy, Emmental, Switzerland, holes, health, } \\
\text { strength }\end{array}$ \\
\hline
\end{tabular}

Source: authors' elaboration

Word "cheese" is mostly associated with words nature, health and sheep. Despite the fact that only a little number of produced cheeses are sheep, when the word cheese is presented, consumers probably see typical Slovak farm-to-Table products as parenica or korbaciky. Another important association is Liptov. It is the mountain region in the north of Slovakia, typical for sheep farming, shepherds and chalets. From these associations we can conclude that sheep cheeses are very popular in the country. Other associations concern the most favourite types of cheese among consumers. Above mentioned types are very common in supermarkets and other stores and are easily available. Parenica and korbaciky are typical as farm-to-Table products in mountain regions of High Tatras and Liptov. They are typical Slovak products and are very popular among consumers. Surprisingly, cow cheese (emmental type) is mostly associated with cartoon characters Tom and Jerry. Other associations are connected with health and strength (like other milk products) and also with mountains, but not in Slovakia but in Switzerland. The cow cheese from the picture with big holes inside is typical for Switzerland and is very often presented in television (in cartoons and movies).

Differences in evaluation of logos for each product were found between two groups of respondents. Results are showed in following Figures (Fig. 6 - Fig. 11). 

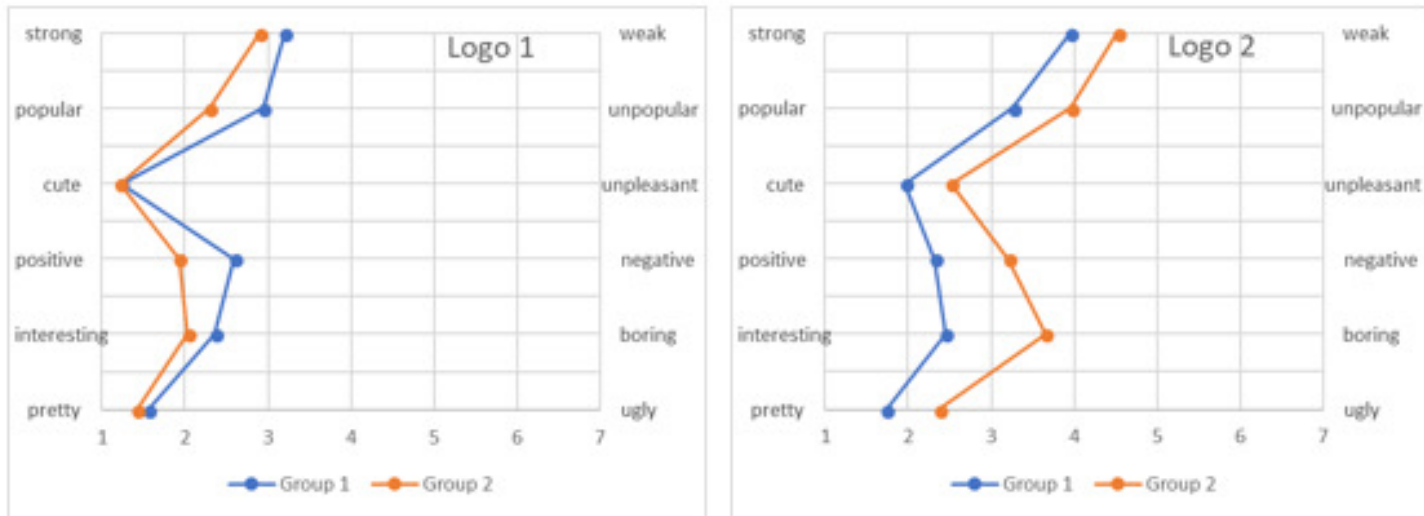

Source: authors' elaboration

Fig. 6. Evaluation of „Parenica” logos on the scale of semantic differential by two groups of respondents
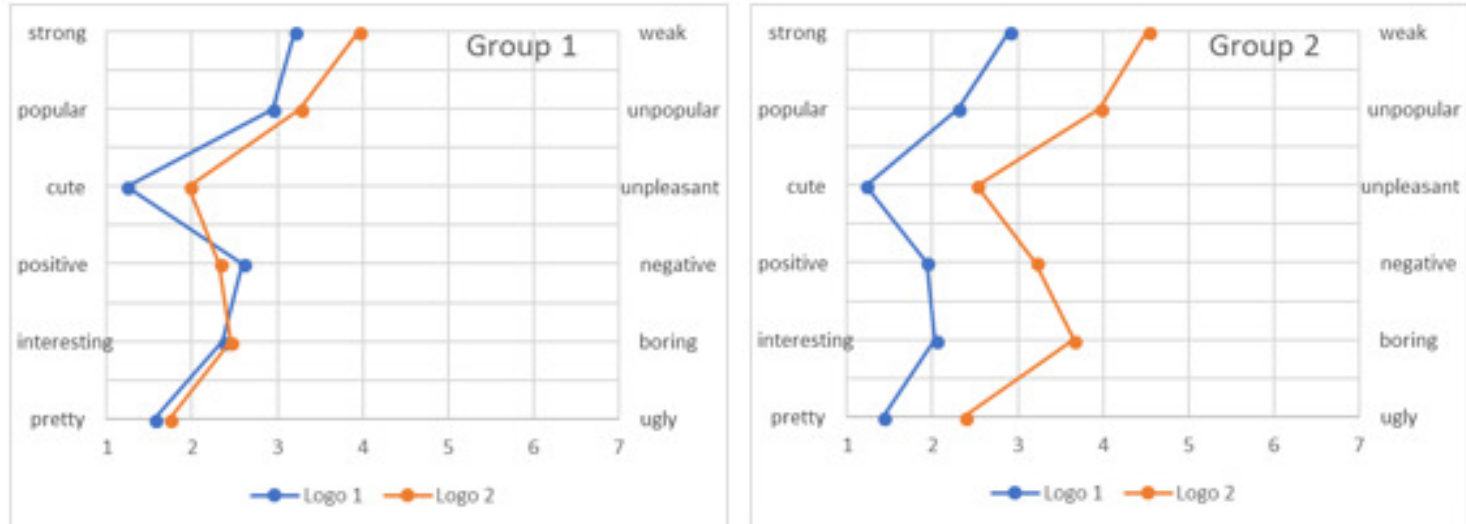

Source: authors' elaboration

Fig. 7. Comparison of evaluations for each „Parenica” logo

The first evaluated logos were logos for "Parenica” sheep cheese. The first designed logo (with sheep) was more positively evaluated by respondents who were told to choose the logo for the farmto-Table product. The second logo (with a mouse, which is holding a parenica cheese) was more positively evaluated by respondents who were not given any information about the product. We can assume that the group without any information about the product was not influenced by associations connected with farm-to-Table products, that is why they evaluated also other visual cues than explicit associations. The first logo was in general evaluated as more pretty (by both groups of respondents), but in the group of respondents who thought that the logo is for the farm-to-Table product the difference in evaluations is more obvious. 

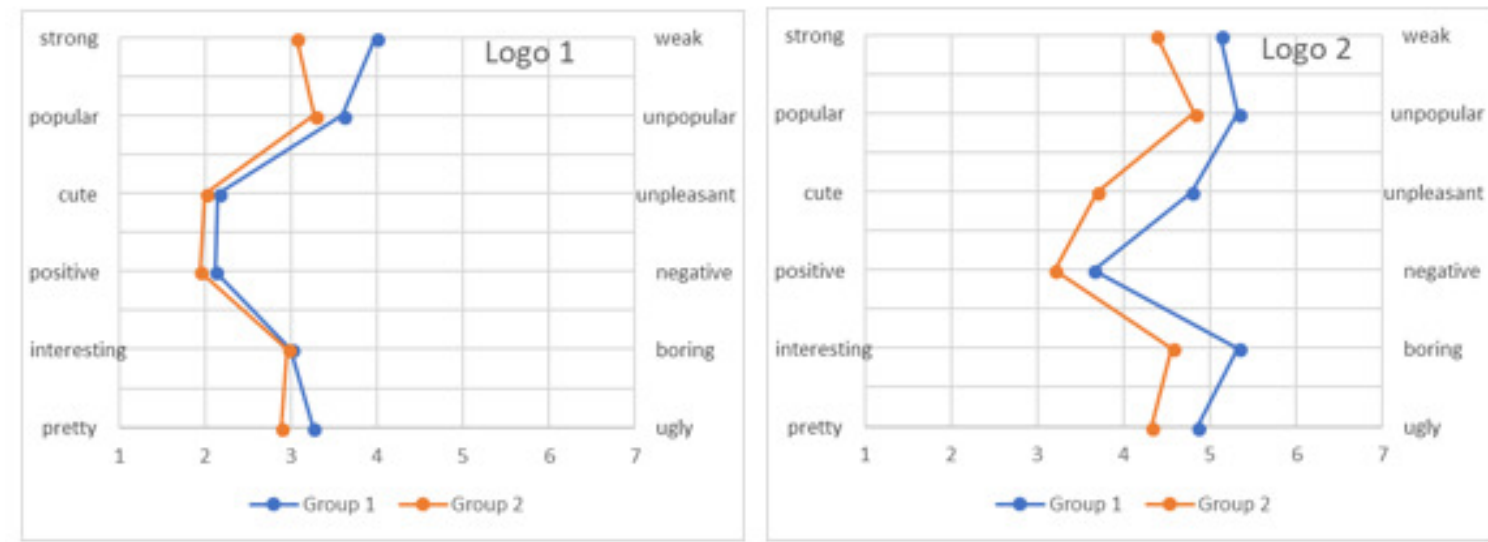

Source: authors' elaboration

Fig. 8. Evaluation of "Korbaciky" logos on the scale of semantic differential by two groups of respondents
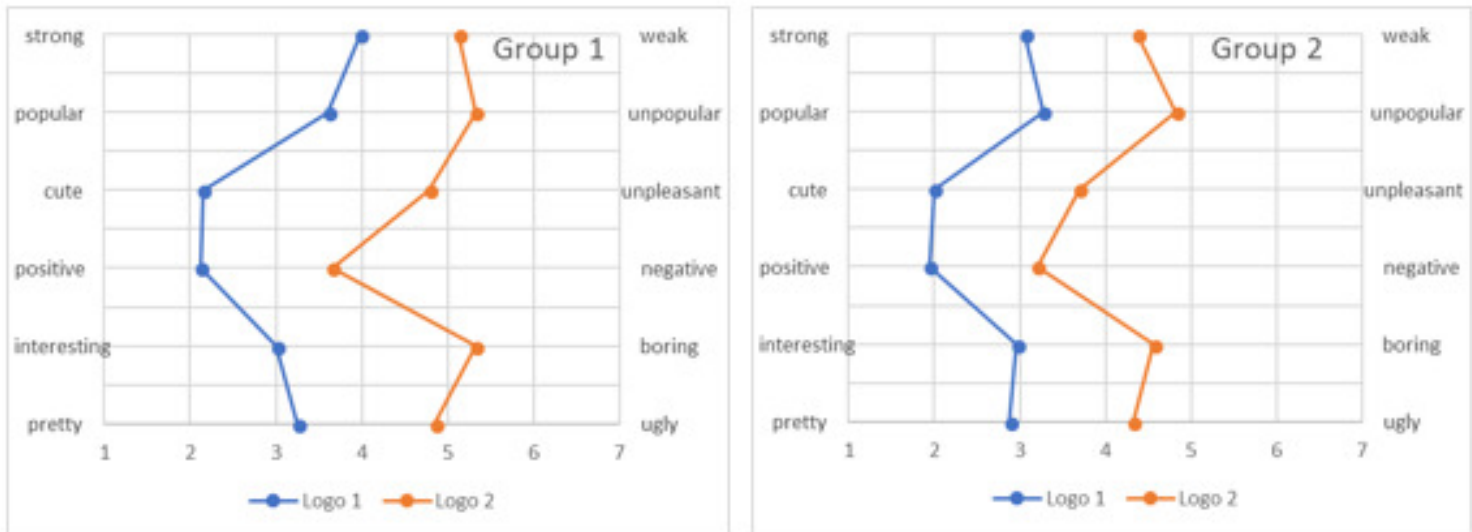

Source: authors' elaboration

Fig. 9. Comparison of evaluations for each „Korbaciky” logo

The logos for "Korbaciky" sheep cheese both contain associated features, but the first one contains also traditional national ornaments. Because both logos contain most popular associations, they are evaluated very similarly. There are not significant differences in evaluation of the first logo between groups. The second logo is more positively evaluated by the group of respondents who were told to choose a logo for the farm-to-Table product. The logo with traditional ornaments is more popular in both groups. We can assume that the more associated features we place on the packaging, the more positively is this packaging perceived by consumers.
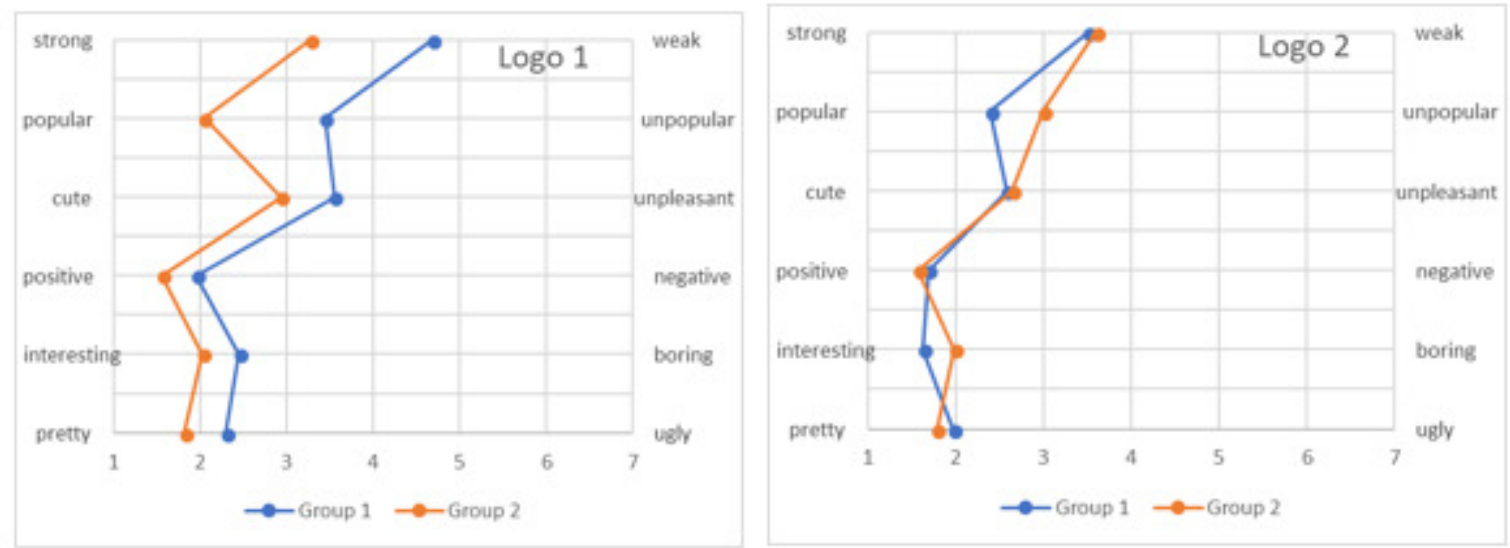

Source: authors' elaboration

Fig. 10. Evaluation of "cow cheese" logos on the scale of semantic differential by two groups of respondents 

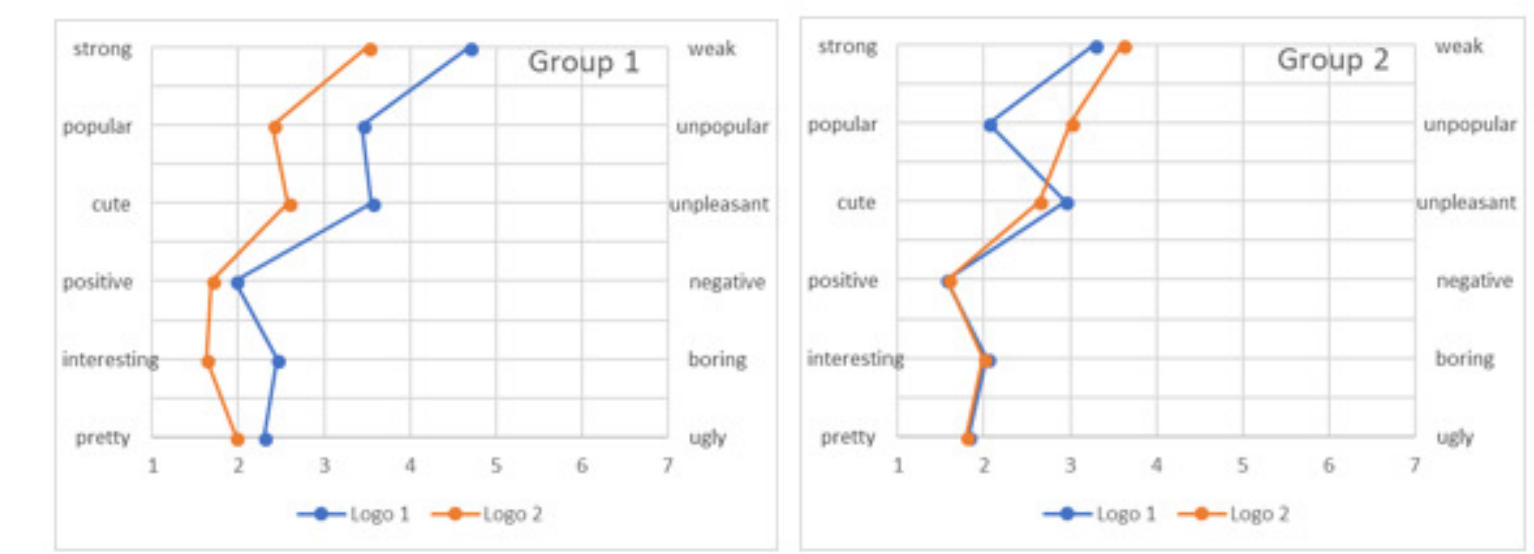

Source: authors' elaboration

Fig. 11. Comparison of evaluations for each "cow cheese" logo

The last evaluated logos were designed for the cow cheese. The first one represents traditions, nature and natural motives. The second one contains Jerry the mouse from the cartoon Tom\&Jerry. The first logo was more positively evaluated by the respondents who were told to choose the logo for the farm-to-Table product. The second one, with Jerry, was positively evaluated by both groups of respondents (most probably because of the strong association). The group of respondents who were not given any other information about the product evaluated more positively the logo with Jerry. We can assume that without additional information, the association is stronger than national and natural motive. The second group of respondents is ambivalent. On the one side, the farm-toTable product is associated with nature and culture, on the other hand the association with Jerry is strong enough.

\section{Conclusions, proposals, recommendations}

1) There is little doubt that the impact of packaging on the consumer behaviour is considerable. If we want to get the right product to the right consumer, the right packaging can help a lot. This is even more important when we talk about the support for little producers and farmers who are very often not able to sell their production and they do not have resources for expensive marketing campaigns.

2) Similar research about the influence of the packaging on the consumer behaviour have been conducted many times. Many authors, e.g. Fazio et al. (1982), Higgins (1996), Fazio and Olson (2003), Jain and Posavac (2004), Gelici-Zeko et al. (2012) Singh and Verma (2017), Jaeger et al. (2018), Rybanska et al. (2018) etc., found out that associations and provided information significantly influence consumers' perception and decision-making process. Previous experiences are important as well, mainly for the creation of associations with selected products or brands.

3) From our study we can conclude that features and visual cues that create the strongest associations in the mind of a consumer can significantly influence the overall perception of the product. When a consumer can find an association (a sound, a picture, a memory etc.) inside his subconscious mind, we can assume that there is an emotional connection present.

4) Because milk and milk products are most commonly associated with traditional, cultural and natural motives, these features can help to sell them the most. We recommend conducting brief association experiments in focus groups before the development of particular packages. These experiments are not financially demanding and can in many cases replace also expensive marketing research. 


\section{Acknowledgement}

The paper is a part of the research project APVV-16-0244 "Qualitative factors affecting the production and consumption of milk and cheese", solved at the Department of Marketing and Trade, Faculty of Economics and Management, Slovak University of Agriculture in Nitra.

\section{Bibliography}

1. Clegg, B. (2000). Capturing Customers' Hearts: Leave Your Competition to Chase Their Pockets. New York: Prentice Hall.

2. Dhar, R. (2012). The Irrational Consumer: Four Secrets to Engaging Shoppers. Retrieved: https://www.huffingtonpost.com/ravi-dhar/psychology-shopping_b_1280341.html

3. Dijksterhuis, A., Smith, p. K., Van Baaren, R. B., Wigboldus, D. H. (2005). The Unconscious Consumer: Effects of Environment on Consumer Behavior. Journal of Consumer Psychology, 15(3), pp. 193-202.

4. Fazio, R. H., Chen, J., McDonel, E. C., Sherman, S. J. (1982), Attitude Accessibility, Attitude-Behaviour Consistency, and the Strenght of the Object-Evaluation Association. Journal of Experimental Social Psychology, 10(1), pp. 139-148.

5. Fazio, R. H., Olson, M. A. (2003). Implicit Measures in Social Cognition Research. Their Meaning and Use. Annual Review of Psychology, 54, pp. 297-327.

6. Fitzsimons, G. J., Hutchinson, J. W., Alba, J. W., Chartrand, T. L., Huber, J., Kardes, F. R., Menon, G., Raghubir, P., Russo, J. E., Shiv, B., Tavassoli, N. T., Williams, p. (2002). Non-conscious Influences of Consumer Choice. Marketing Letters, 13, pp. 269-279.

7. Gelici-Zeko, M. M., Lutters, D., Klooster, R., Weijzen, p. L. G. (2012). Studying the Influence of Packaging Design on Consumer Perceptions (of Dairy Products) Using Categorizing and Perceptual Mapping. Packaging Technology and Science.

8. Higgins, E. T. (1996). Knowledge Activation: Accessibility, Applicability, and Silence. In E. T. Higgins, A. Kruglanski (Eds.), Social Psychology: Handbook of Basic Principles. New York: Guilford.

9. Jacob, C., Guéguen, N., Boulbry, G. (2011). Presence of Various Figurative Cues on a Restaurant Table and Consumer Choice: Evidence for an Associative Link. Journal of Foodservice Business Research, 14(1), pp. 47-52.

10.Jaeger, S. R., Lee, P., Ares, G. (2018). Product Involvement and Consumer Food-Elicited Emotional Associations: Insights from Emoji Questionnaires. Food Research International, 106, pp. 999- 1011.

11.Jain, S. P., Posavac, S. S. (2004). Valenced Comparisons. Journal of Marketing Research, 41(1), pp. 46-58.

12. Krishna, A., Morrin, M., Sayin, E. (2014). Smellizing Cookies and Salivating: A Focus on Olfactory Imagery. Journal of Consumer Research, 41(1), pp. 18-34.

13. Kubala, J. (2018). 5 Ways that Drinking Milk Can Improve Your Health. Retrieved: https://www.healthline.com/nutrition/milk-benefits

14. Levin, I. p. (1987). Associative Effects of Information Framing. Bulletin of the Psychonomic Society, 25(2), pp. 85-86.

15. Masar, I. (2018). Mlieko [Milk]. Retrieved: http://www.vuepp.sk/dokumenty/komodity/2018/Mlieko06_18.pdf [in Slovak].

16. Rybanska, J., Nagyova, L., Horska, E. (2018). Conventions and Stereotypes as Key Perception Factors Influencing the Choice of Selected Farm-to-Table Products. 8th International Scientific Conference of Business Faculty, Durres, Albania [in press].

17.Singh, A., Verma, p. (2017). Factors Influencing Indian Consumers' Actual Buying Behaviour Towards Organic Food Products. Journal of Cleaner Production, 167, pp. 473-483.

18. Ware, M., Wilson, D. R. (2017). All About Milk. Retrieved: https://www.medicalnewstoday.com/articles/273451.php 